\title{
A FAMÍLIA DO PORTADOR DE TRANSTORNO MENTAL: IDENTIFICANDO RECURSOS ADAPTATIVOS ${ }^{1}$ THE FAMILY OF A PERSON SUFFERING FROM A MENTAL DISORDER: IDENTIFYING ADAPTIVE RESOURCES LA FAMILIA DEL PORTADOR DE TRANSTORNO MENTAL: IDENTIFICANDO RECURSOS ADAPTATIVOS
}

\author{
Vanessa Navarini ${ }^{2}$, Alice Hirdes ${ }^{3}$
}

\footnotetext{
${ }^{1}$ Trabalho apresentado como requisito à obtenção do título de Enfermeiro na Universidade Regional Integrada do Alto Uruguai e das Missões - Campus de Erechim, em 2005.

${ }^{2}$ Enfermeira do Centro de Atenção Psicossocial - I Regional Novos Horizontes de Jacutinga. Rio Grande do Sul, Brasil.

${ }^{3}$ Mestre em Assistência de Enfermagem. Docente da Universidade Luterana do Brasil - Campus Gravataí. Orientadora do estudo. Rio Grande do Sul, Brasil.
}

PALAVRAS-CHAVE: Saúde mental. Adaptação psicológica. Família.
RESUMO: Este estudo teve como objetivo compreender o significado de vivenciar a doença mental na família com vistas a identificar os recursos adaptativos da mesma. Trata-se de um estudo exploratório descritivo com abordagem qualitativa, realizado em um Centro de Atenção Psicossocial do interior do Estado do Rio Grande do Sul. A amostra do estudo constituiu-se de 10 familiares do cotidiano de portadores de transtorno mental. Os resultados apontam as dificuldades de manejo da família em situações de crise, a culpa pela doença; a solidão e o desamparo, quando do aparecimento dos primeiros sintomas; os sentimentos, como o medo, a tristeza, a vergonha e a raiva, assim como, o afeto e o cuidado presentes. Conclui-se que o suporte de informações para os familiares amenizaria o sentimento de culpa, diminuindo em grande parte o sofrimento dos familiares, assim como, a necessidade de a família ser co-partícipe do tratamento e da reabilitação.
KEYWORDS: Mental health. Adaptation, psychological. Family.

PALABRAS CLAVE: Salud mental. Adaptación psicológica. Familia.
ABSTRACT: This study aimed to better understand what it means for a family to live with mental illness, seeking to identify adaptive resources. It is an exploratory, descriptive, qualitative research that was carried out at a Psycho-Social Care Center in Rio Grande do Sul, Brazil, from June to July of 2005. This sample was comprised of 10 family members of people who have a mental illness. Data analysis was carried out via ordering, classification, and final analysis. The results point out the difficulties the family has in handling crises; the guilt they feel due to the illness; the loneliness and abandonment felt when the first symptoms appear; and feelings such as fear, sadness, shame, and anger; as well as affection and care present. I conclude that providing information support for family members would ease the feeling of guilt, as well as the family's need to be a co-participant during treatment and rehabilitation.

RESUMEN: El objetivo del presente estudio fue comprender el significado de vivenciar la enfermedad mental en familia e identificar los recursos adaptativos. Se trata de un estudio exploratorio descriptivo cualitativo, realizado en un Centro de Atención Psico-social en Rio Grande do Sul, Brasil, de junio a julio de 2005. La muestra del estudio se constituyó de 10 familiares de portadores de trastorno mental. El análisis de los datos fue realizado por ordenación, clasificación y análisis final. Los resultados señalan: dificultades de manejo de la familia en situaciones de crisis; culpa por la enfermedad; soledad y desamparo al aparecimiento de los primeros síntomas; sentimientos como miedo, tristeza, vergüenza y rabia; así como, afecto y cuidado presentes. Se concluye que el soporte de informaciones para los familiares reduciría el sentimiento de culpa, así como, la necesidad de la familia ser copartícipe del tratamiento y de la rehabilitación.
Alice Hirdes

Endereço: Av. Icaraí, 1048, ap. 901

90180-000 - Cristal, Porto Alegre, RS, Brasil

E-mail: alicehirdes@gmail.com
Artigo original: Pesquisa Recebido em: 1 de novembro de 2007 Aprovação final: 3 novembro de 2008 


\section{INTRODUÇÃO}

A família é uma instituição social que vem modificando a sua estrutura através da história e tem finalidades diversas numa mesma época e lugar. Apesar dos possíveis conflitos, a família, no entanto, é única em seu predominante desenvolvimento da sociabilidade, da afetividade e do bem-estar físico dos seus seres, sobretudo durante a infância e a adolescência. ${ }^{1}$

Não se pode desvincular o indivíduo do meio em que vive, uma vez que a família, como grupo, previne, tolera e corrige problemas de saúde. Desse modo, não se pode separar a doença do contexto familiar e por ser um elemento tão imprescindível, a família deve ser compreendida como uma aliada da equipe de saúde, atuando como um recurso na promoção do conforto, para o paciente adquirir confiança e, assim, investir na sua recuperação. ${ }^{2}$

Somente a partir dos anos 1950, começou a se manifestar um grande interesse pelos aspectos sociais e familiares da doença mental. Alguns trabalhos realizados na psiquiatria sobre as relações familiares e a doença mental influenciaram a maneira tradicional de cuidar do portador de doença mental, como único responsável pela sua doença, o que veio contribuir para a compreensão e recuperação destas pessoas. ${ }^{3}$

Já na década de 80, alguns estudiosos observaram que essas famílias estavam conseguindo prestar cuidados, tais como: alimentar, administrar a terapêutica medicamentosa e confortar o seu familiar doente, os quais, anteriormente, eram prestados por instituições estatais. A partir daí, os pesquisadores observaram que as famílias, por si próprias, começaram a buscar respostas às suas necessidades para poder cuidar do seu familiar. O ponto positivo até agora observado em relação à inclusão da família neste cuidado está associado, fundamentalmente, aos baixos números de reinternações. Estudos evidenciam que as famílias atendidas ao nível ambulatorial têm mais alívio da sua sobrecarga do que aquelas atendidas ao nível hospitalar. Os pesquisadores concluíram, ainda, que o cuidado domiciliar aliviou a ansiedade da família, favorecendo o aprendizado de como cuidar do seu familiar doente através de um ensino contextualizado, direto e adaptado às suas necessidades de aprendizagem. ${ }^{4}$

Alguns profissionais de saúde começaram a dar-se conta da necessidade de reconhecer a família como um membro integrante do cuidado prestado ao seu familiar doente, o que influi favo- ravelmente no prognóstico da doença. No entanto, parece difícil cuidar da família do ser portador de doença mental, sem ter uma compreensão prévia do significado de vivenciar esta doença. Isto porque, até bem poucos anos atrás, os profissionais de saúde e as políticas de saúde mental não eram voltadas para as famílias, como um grupo capaz de ajudar na recuperação do seu familiar doente e também necessitando de ajuda. ${ }^{4}$

As abordagens terapêuticas antigas, muitas vezes alienaram os indivíduos com desabilidades mentais severas de um sistema de suporte natural e em muitos casos reforçaram o abandono. Os modelos de tratamento psicodinâmico derivam dos paradigmas que tendem a excluir as famílias de informações e do envolvimento no processo terapêutico. Os modelos de terapia familiar, por outro lado, têm envolvido os membros da família no tratamento com a improvável premissa de que os sintomas da esquizofrenia ou de desordens afetivas irão desaparecer mediante a manutenção da homeostase de um ambiente familiar disfuncional. Esta premissa resultou em frustração às famílias e tem sido repudiada como arcaica pela maioria dos terapeutas familiares. ${ }^{5}$

$\mathrm{O}$ advento da terapia familiar trouxe as famílias para dentro do processo do tratamento, mas perpetuou a visão da identificação do paciente como vítima e portador da psicopatologia da família. Numerosos estudos têm sido conduzidos para confirmar a hipótese subjacente da relação entre a psicodinâmica e as teorias dos sistemas familiares. Pesquisas utilizando rigorosos modelos de replicação têm falhado na confirmação da aproximação de achados de estilos de comunicação desviante. Estas pesquisas desenvolvidas durante um quarto de século com pessoas com esquizofrenia evidenciam que $75 \%$ a $80 \%$ das mães encontradas não podem remotamente ser encaixadas na descrição de esquizofrenizantes. A noção de família patológica tem produzido efeitos danosos para ambos, familiares e pacientes. ${ }^{5}$

A doença significa mais do que um conjunto de sintomas, possui outras representações de ordem simbólica, moral, social ou psicológica para o doente e a família. A família demonstra necessidade de conhecimento sobre a doença, de seus sintomas e efeitos, passando a enfrentar a doença com mais segurança e menos sofrimento. ${ }^{6}$

Desta forma, este estudo teve como objetivo compreender o significado de vivenciar a doença mental na família, com vistas a identificar os recursos adaptativos utilizados. 


\section{METODOLOGIA}

Esta pesquisa foi realizada num Centro de Atenção Psicossocial (CAPS) do interior do Estado do Rio Grande do Sul, implantado em agosto de 2002, através da Secretaria Municipal de Saúde. Com relação às características demográficas, trata-se de uma cidade de médio porte, com aproximadamente 90 mil habitantes, a população etnicamente composta de descendentes de italianos, alemães, poloneses e afro-brasileiros. Quanto às condições sócio-econômicas, assenta-se na agricultura o sustentáculo econômico, seguido de indústrias e prestação de serviços.

Os sujeitos do estudo foram familiares de usuários do CAPS. Neste modelo de atenção que atende prioritariamente pacientes portadores de transtornos psíquicos graves, o usuário participa de seu projeto terapêutico e, inclui-se ainda a participação da família e da comunidade, já que a doença não é vista como algo individual. Uma vez admitido no CAPS, realiza-se com o usuário e sua família um contrato terapêutico, no qual é explicado para os familiares o plano de tratamento individualizado, quais as atividades que serão realizadas; é solicitada autorização para os familiares para fazer os exames necessários; é explicada a declaração e o termo de compromisso, e, de acordo com as suas necessidades, o paciente poderá participar das seguintes modalidades terapêuticas: atendimento individualizado, grupo terapêutico verbal, grupo de terapia ocupacional, atendimento familiar e acompanhamento medicamentoso.

Trata-se de um estudo exploratório descritivo de abordagem qualitativa. A amostra do estudo constituiu-se de 10 familiares que fazem parte do dia-a-dia do portador de transtorno mental, e obedeceu ao seguinte critério de inclusão: estar vinculado ao grupo de familiares do CAPS. A coleta foi realizada entre os meses de abril e maio de 2005. Para a análise dos dados foi seguido o caminho metodológico: ordenação, classificação e análise final dos dados. ${ }^{7}$

A ordenação dos dados engloba tanto as entrevistas, como o conjunto do material institucional apreendido. Essa etapa consiste na transcrição de fitas-cassete; releitura do material; organização dos relatos em determinada ordem, de acordo com a proposta analítica. A etapa seguinte, a classificação dos dados será operacionalizada através da leitura exaustiva e repetida dos textos. Através deste exercício se fará a apreensão das "estruturas de relevância" a partir das falas dos sujeitos do estudo. Nestas estão contidas as idéias centrais dos entrevistados.

A análise final permite fazer uma inflexão sobre o material empírico e o analítico, num movimento incessante que se eleva do empírico para o teórico e vice-versa. Esta "dança" que promove relações entre o teórico e o empírico, o concreto e o abstrato o geral e o particular, a teoria e a prática é o verdadeiro movimento dialético visando o concreto pensado. O produto final é sempre provisório, e condicionado pelo momento histórico, pelo desenvolvimento científico, por sua pertinência a uma classe social e pela capacidade de objetivação. ${ }^{7}$

Os familiares encontram-se identificados como E1, E2, E3... assegurando, assim, o anonimato de cada sujeito entrevistado. Os entrevistados assinaram o Termo de Consentimento Livre e Esclarecido. O projeto foi submetido à avaliação do Comitê de Ética em Pesquisa da Universidade, sob o protocolo No $008-01 / \mathrm{TCH} / 05$, tendo sido aprovado. Foram respeitados os aspectos éticos referentes à pesquisa com seres humanos, conforme determina a Resolução No 196/96. ${ }^{8}$

\section{ANÁLISE E DISCUSSÃO DOS DADOS}

$\mathrm{Na}$ análise dos dados, depois de extraídas as estruturas de relevância das falas dos atores sociais, as mesmas foram identificadas como as seguintes áreas temáticas: sobrecarga familiar decorrente da doença; diversidade de sentimentos gerados na família; culpabilização pela doença do familiar; interação familiar e profissionais da saúde.

\section{Sobrecarga familiar decorrente da doença}

Observa-se no discurso dos pesquisados, que a experiência de ter um membro da família com doença mental, mobiliza esta família como um todo no seu dia-a-dia, independente da forma como ela vem se constituindo, em razão de ser muito difícil necessitar desse familiar e ele não poder colaborar no cotidiano familiar. As falas a seguir demonstram o dia-a-dia do paciente com a família.

Tem dias que ela é bem mais ativa, tem dias que ela está parada, tem que incentivar ela para fazer alguma coisa (E1).

Varia muito, tem vezes assim que ela é mais participativa, tem vezes que não, que ela se isola da gente, assim, ela, você não pode compartilhar algum problema com ela que vai se estressar mais ainda, então depende muito, quando ela quer, ela vem até a gente, senão ela fica se isola o dia inteiro (E10). 
Os entrevistados relatam os diversos comportamentos que o familiar portador de transtorno mental apresenta, inclusive, a agressividade presente no dia-a-dia de seus familiares. Destacam como causa dessa agressividade o nervosismo, a dificuldade para o entendimento, a revolta e até o desejo de isolamento.

Ela fica muito isolada, ela é muito nervosa, as vezes ela é até agressiva comigo. Às vezes eu perco até o serviço para ficar com ela, cuidando, porque não posso deixar ela sozinha, ela é muito nervosa, tenho que deixar uma pessoa cuidando dela, no dia-a-dia ela é muito nervosa, muito agitada, às vezes levanta da cama bem, daqui a pouco senta e já começa a ficar agitada (E5).

A presença de uma pessoa com transtorno mental produz um impacto nos outros membros da família, tendo em vista que, os familiares ficam sobrecarregados por demandas que envolvem a função de acompanhar seus membros adoecidos e cuidar deles. Essa sobrecarga familiar é sentida não somente nos aspectos emocional e físico, mas também nos encargos econômicos. Em geral, os pacientes psiquiátricos apresentam grandes obstáculos para produzir economicamente, o que implica uma situação de dependência da família. São altos os custos para se manter uma pessoa nesta situação, além de limitar o acesso do cuidador no mercado de trabalho, devido às restrições de horários disponíveis. ${ }^{6}$

Para as famílias cada "louco" tem seu dono e, nesse sentido, são pressionadas socialmente a se encarregarem do seu. A rua parece representar uma condenação extrema. O imaginário familiar parece ter uma função como a "nau dos loucos" na sociedade. Significa um não-lugar ou um lugar de perdição e de perdidos, pelo anonimato e negligência que lhe são próprios. ${ }^{9}$

[...] a vida dele é a rua, não participa muito conosco em casa, ele não é assim de ajudar em casa [...] família para ele é a última coisa, ele quer é rua, ouvir o que os outros dizem, ele é bastante nervoso, briga na rua (E6).

No imaginário social, o "louco" solto na rua expressa um perigo, por seu comportamento considerado imprevisível e violento, ou seja, há uma homogeneização do "louco" e da loucura como expressão do perigo. Na contramão desse imaginário social, é possível observar que diferente do que se propaga, socialmente, as famílias, em sua maioria, têm outra leitura dessa realidade, ou seja, preocupam-se pela multiplicidade de riscos que a rua representa para o doente, sobretudo se for do sexo feminino: ser estuprada, morrer afogada num rio, ser agredida num canto qualquer, ter que dormir num banco de praça, ao relento. Enquanto a rua distante e fora do controle dos familiares constitui um risco, a rua das proximidades, havendo boas relações com a vizinhança e parentes, pode converter-se em uma rede de suporte de ajuda material, afetiva e de cuidados. ${ }^{9}$

Do ponto de vista emocional, o estresse, as vivências de instabilidade e insegurança, os conflitos freqüentes nas relações fazem parte do cotidiano dessas pessoas. Além disso, é comum os familiares se distanciarem das atividades sociais, motivados pela vergonha, cansaço ou frustração. ${ }^{6}$

[...] o comportamento é muito difícil, a gente não tem vida social, a gente vive mais em função dele, dai durante o dia a gente atende ele [...] de noite a gente não sai para ficar com ele, para ele não sair, daí no final de semana a gente vai mais no interior, porque é o lugar que ele gosta (E6).

O familiar vai se desgastando pela convivência com a pessoa portadora de transtorno mental, acarretando sobrecarga física e emocional, privando-se da sua própria vida para poder prestar um cuidado adequado. O comportamento imprevisível da pessoa debilita as expectativas sociais e origina incertezas e dificuldades no grupo familiar e na sociedade.

Considerando os depoimentos dos entrevistados, pensamos que há uma sobrecarga da família, em especial diante da agudização dos sintomas. Evidencia-se nas falas as mudanças de comportamento que uma pessoa em sofrimento psíquico apresenta, situação esta de difícil entendimento tanto para a família como para a sociedade em geral. O desgaste, tensões e conflitos causados por uma pessoa mentalmente perturbada constituem os maiores problemas que a família enfrenta. A imprevisibilidade do paciente em seus comportamentos é outra fonte de tensão dentro e fora de casa. ${ }^{10}$

[...] a gente queria achar uma maneira, para ela ficar feliz, para ela não ter essas crises, mas o comportamento dela não é fácil, então a dificuldade é se encontrar, ela gostaria de ter amigos, amizades, mas ela não sabe viver no meio dessas amizades (E7).

À medida que ocorrem recaídas no quadro psicopatológico do portador de transtorno mental, algumas famílias vão aprendendo a manejar suas próprias dificuldades, praticamente pelo ensaio e erro. Também aprendem a manejar alguns sintomas do portador de transtorno mental, tal como a agressividade. Algumas famílias ainda conseguem prever o início de uma crise psiquiátrica à medida que a enfermidade se estabiliza. ${ }^{9}$ 
[...] o dia-a-dia a gente convive com ela ali, a gente tenta levar ela sempre numa boa, quando ela fica bastante nervosa eu pego as crianças e a gente sai, quando ela está bastante nervosa, ela reclama de tudo, daí ela vai empurrando tudo, vai derrubando (E1).

Há sobrecarga física e psíquica em função da convivência com o doente mental, pois é necessário que os integrantes do grupo familiar dêem conta desses comportamentos imprevisíveis da melhor forma possível para não acarretar frustração, porque o transtorno mental provoca deslocamentos nas expectativas e nas relações afetivas entre as pessoas.

De acordo com os depoimentos, é a perda do controle do comportamento que faz a família se desequilibrar, porque, muitas vezes, os sintomas põem em risco o funcionamento normal do cotidiano da família. Esta situação de instabilidade gerada pela crise reflete as dificuldades em lidar com o comportamento da pessoa com transtorno mental, com os sintomas da doença. Na sua maioria, sentem-se sós para enfrentar os problemas e desinformadas quanto ao modo de agir frente a eles, ficando desamparadas, quando aparecem os primeiros sintomas da doença. Sentem-se vítimas do destino.

\section{Diversidade de sentimentos gerados na família}

Abordamos, nesta área temática, a devastação causada quando do diagnóstico, quando a família toma conhecimento da doença mental. O diagnóstico de doença mental gera um sentimento inexplicável, um vazio, uma baixa condição da qualidade de vida. Sentimentos derivados passam a fazer parte desse cotidiano, como o medo, a tristeza, a vergonha e a piedade, um aglomerado de ações ou efeitos do sentir.

O sofrimento expresso pela família no cotidiano está presente no relato da fala do entrevistado E2, na qual transparece a empatia e a sensibilidade com a dor do outro, a preocupação em compreender reações e mensagens emitidas implicitamente pela família e o doente, a busca, nesta relação, de adequar o ato de cuidar às necessidades próprias deste familiar doente. Os familiares sofrem, porque têm consciência da doença. A entrevista evidencia um sentimento de tristeza misturado com carinho pelo portador de transtorno mental, como se pode observar nesta fala: [...] sentimentos que ele desperta para nós: há muito tempo a gente sente não épena, é um sentimento assim, ainda por mais que a gente tente lutar contra isso a gente não consegue aceitar essa doença. Para tratar uma pessoa esquizofrênica a sensação é de como se nós caminhássemos em cima de ovos, porque você nunca sabe como ele vai acordar, você nunca sabe como vai ser a atitude dele, para nós ele é amor, alegria, para nós ele faz parte da família, para nós ele é tudo, é um pedaço da gente (E2).

A família é atingida profundamente pelo sofrimento, sentimento que perpassa o seu viver em todos os níveis, tornando-se o companheiro de todas as horas, ao longo da trajetória da doença do familiar. O sofrimento manifesta-se de diferentes formas e intensidades, deixando marcas profundas no mundo da vida da família. O primeiro impacto é experienciado por ocasião do diagnóstico. Os sentimentos de sofrimento e insegurança são companheiros constantes em todas as etapas do tratamento, e na perspectiva acerca do futuro. ${ }^{4} \mathrm{~A}$ fala a seguir torna manifesto tais sentimentos.

Ele não me deixa ter muito sentimento por ele, porque ele é bastante brabo, não concorda com nada, ele briga, quando eu vejo ele quietinho, dai eu sofro também, porque eu vejo que ele está assim que ele não tem culpa, queria fazer alguma coisa por ele [...] quando ele está muito brabo comigo daí eu também fico com raiva, fico revoltada (E6).

O sofrimento e a dor levam a família a assumir, como um ser autêntico, esta realidade existencial. Quando o elo de união familiar se traduz em afeto e solidariedade, os vínculos familiares são reforçados, conferindo energia para enfrentar a caminhada imposta pela doença. ${ }^{4}$

Ao assumir o cuidado do doente podem emergir sentimentos e emoções latentes, provocando desequilíbrio e sofrimento. A partir daí, surge uma nova dinâmica no modo de ser da família, e ela adquire forças para aceitar e ajudar o membro portador, aprendendo a conviver com a doença, conforme os depoimentos: [...] a gente sente dó dele, mas não dá demonstração (E3). [...] eu fico triste quando vejo ela daquele jeito (E5). [...] quando ela está em crise a gente sofre, a gente tenta levar ela de cá para lá. [...] tentar acalmá-la (E8).

A preocupação com o bem-estar do seu familiar pode ser uma constante na existência destas famílias, buscando, em suas tomadas de decisão, confortá-lo. O cuidado parece constituir a essência da relação com o outro neste convívio cotidiano, sendo considerado como prioritário diante de qualquer outra situação que possa vir a ocorrer em sua vida. Esta preocupação 
evidencia-se no contato direto com as famílias que vivenciam o processo de doença com profunda dor, mostrando-se inseguras quanto ao que fazer diante do ser que amam. ${ }^{11}$

Um aspecto que deve ser considerado diz respeito à preocupação manifestada pelos familiares, geralmente os mais idosos, em relação ao que irá acontecer no futuro, caso eles fiquem incapacitados ou venham a falecer. ${ }^{5}$

Eu penso muito nela, porque ela é querida e tudo, mas você tem que entender ela, ela não entende a gente, eu só penso o dia que eu faltar quem cuidará dela, como será que ela vai ser tratada ou entendida porque é a gente que tem que entender ela, eu sinto muito por ela (E9).

As mudanças causadas pelo diagnóstico e tratamento geram sentimentos que, por vezes, são difíceis de lidar, provocando um desequilíbrio no mundo da família. A mudança de um integrante afeta todos os outros. A compreensão da luta enfrentada no processo de ser doente estimula a família a cooperar e a dar-lhe apoio, encorajando-o ao tratamento e à superação das intercorrências que possam surgir. ${ }^{4}$

O que eu posso fazer por ela eu faço, às vezes eu fico sem sabe o que fazer, eu fico às vezes mais mal do que ela, quando ela está daquele jeito, o que eu posso fazer por ela eu faço, é muito sofrido, sofro vendo ela daquele estado (E4).

O mundo da vida familiar é radicalmente modificado com a doença do filho. A relação com o outro sofre alterações, surgem novos papéis, a articulação e a circulação no mundo da família passam a ter novas regras, gerando, por vezes, muito sofrimento aos seus membros. As relações com o mundo externo também ficam abaladas, exigindo uma readaptação da família frente às limitações impostas pela doença. ${ }^{6}$

Percebe-se que a doença mental afeta a vida familiar, o clima emocional, tensionando as ansiedades e os encargos que recaem sobre a família, com efeitos danosos sobre o seu funcionamento, com alteração da dinâmica familiar. A família fica fragilizada, suas relações internas e externas ficam totalmente comprometidas. Entretanto, a família também se revela como um lugar de continência, de afeto, de cuidado, ainda que muitas vezes apareçam sentimentos contraditórios, inerentes à frustração aos encargos objetivos e subjetivos. A família faz uma reflexão sobre suas motivações, seu estilo de vida, seus valores preestabelecidos, anteriores à doença. A vida é vista sob outro enfoque, muitos valores adquirem novo significado.

\section{Culpabilização pela doença do familiar}

É preciso cuidado para não se criar um outro preconceito que atrapalha bastante o relacionamento com uma pessoa doente, que é a idéia de que alguém é culpado pela doença. Isso aparece muito; em razão disto, todo comportamento inadequado é mostrado como resultado de erros. ${ }^{6}$ Isto fica evidenciado nas falas que seguem.

Eu me senti culpada foi assim [...] porque quando ele começou a ficar ruim o médico disse que era problema no parto daí eu me culpei [...] e aí eu fiquei me culpando todo tempo, mas depois eu descobri que não era [...] mas daí em diante eu não fiquei mais preocupada, ninguém pode fazer nada (E6).

Estimulada ou não pelas teorias psicológicas existentes, a culpa revela-se como uma das marcas mais visíveis na vida dessas pessoas. De modo mais ou menos consciente, o familiar culpado costuma mergulhar de cabeça na procura de eventuais erros do passado, buscando incessantemente explicações e sentidos que possam amenizar seu sofrimento. ${ }^{6}$

A gente muitas vezes se acha culpado hoje [...] se fosse hoje, com a experiência que a gente tem, teria incentivado um esporte, ela gostava de natação, quem sabe a gente teria superado [...] se nós tivéssemos investido mais, acompanhado mais, quem sabe hoje ela teria uma desenvoltura, não estaria na situação que ela está [...] quem sabe estaria bem melhor (E7).

A presença de um transtorno mental grave faz com que os parentes mais próximos mergulhem num mar de dificuldades de toda natureza. Eles precisam e pedem ajuda. ${ }^{12} \mathrm{O}$ adoecimento mental de um filho abala, freqüentemente, de forma intensa, a auto-estima dos pais. $O$ filho doente parece representar, para muitos genitores, uma denúncia das falhas do sistema familiar. A ferida no narcisismo dos pais expõe fragilidades e conflitos, estimulando questionamentos relativos à eventual responsabilidade na origem e desencadeamento do quadro psicótico. ${ }^{4}$

Eu acho que eu estava grávida, meu marido me bateu, pode se que fosse aquilo, pode se que não, mas eu fiquei muito chocada, me representa que é por isso que ele ficou assim (E3).

No relato dos familiares evidencia-se a presença de um intenso sentimento de culpa, principalmente dos pais em relação aos filhos. Possivelmente, localiza-se na culpa um dos elementos chaves a ser estudado e pesquisado em maior profundidade para entender as vivências descritas. Nesse sentido, um dos caminhos a ser explorado na tentativa de seguir os rastros da culpabilização dos 
familiares aponta para o processo de constituição da família. Na época que eu tinha problema de alcoolismo, às vezes pode ser um pouco disso [...] pretendo nunca mais ter álcool no meu corpo e cuidar dela, eu me sinto culpado por ela estar nesse estado (E5).

Quando as famílias estão equilibradas emocionalmente, pode ocorrer remissão de alguns sintomas da doença de seu familiar, porque desta forma elas interagem positivamente com os seus membros, acolhendo as recaídas e não se sentindo culpadas. O componente essencial destas mudanças é ajudá-los a olhar além da sua dor. Ajudá-los a reconhecer e apreciar o absurdo da vida. É essencial que eles aprendam não apenas a tolerar, mas também a aproveitar a ansiedade e a dor que tornam a vida real. As famílias devem considerar suas experiências de vida, para que possam crescer individual e coletivamente; independente dos sentimentos que as oprimem, devem criar um ambiente calmo e sadio para dividirem suas ansiedades. ${ }^{4}$

As entrevistas evidenciam a ausência de informação, de divulgação sobre a doença mental. O suporte de informações para os familiares amenizaria o sentimento de culpa, diminuindo em grande parte o sofrimento dos familiares.

\section{Interação familiar e profissionais da saúde}

Os membros da família geralmente se beneficiam de orientações dadas sobre a doença e seu tratamento, e do aconselhamento familiar, que proporciona apoio emocional e dicas práticas sobre como interagir com o portador de transtorno mental. Reuniões com o paciente e com a família também podem ser uma boa fonte de orientação, e são especialmente úteis no aperfeiçoamento das habilidades de comunicação e para o aprendizado de estratégias úteis para enfrentar a doença. Melhorando a forma como a família enfrenta a doença, pode-se reduzir a sobrecarga sobre a família e reduzir os sintomas e as incapacidades do doente.

Entendemos que, apesar de as famílias vivenciarem problemas comuns, principalmente quando possuem um de seus membros afetado pela doença, cada uma delas possui peculiaridades específicas e suas necessidades estão baseadas em sua vivência. É isso que deve caracterizar a proposta de cuidado a ser oferecida pelo profissional. Esta proposta deve ser pautada na realidade e ter em vista a satisfação das necessidades familiares, em busca de uma melhor qualidade de vida de cada membro individualmente e da família como um todo.
Entendemos que os familiares conseguem lidar com menos apreensão e até mesmo oferecer um cuidado de melhor qualidade ao seu familiar doente, quando participam de reuniões onde cada cuidador expressa suas ansiedades e até mesmo as formas de contorná-las, trocando suas experiências, suas dúvidas e recebendo orientações, não só sobre os cuidados, mas também sobre os tipos de assistência que existem para serem prestados em casa, no momento em que se fizerem necessários.

Eu vou sempre nas reuniões, eu venho sempre aqui volta e meia pra falar com a psicóloga com a psiquiatra, sempre tenho orientação delas para como agir com ela quando dá as crises (E5).

Aqui eu estou sendo ajudado, eu recebo muita orientação dos profissionais, dai eles repassame eu tenho como controlar ela tranqüilo em casa (E8).

Observamos que as famílias entrevistadas têm algumas necessidades específicas com relação ao portador de doença mental. Dentre elas destacam-se: a necessidade de aprenderem a relacionarse com o doente mental; compreenderem a doença mental, suas manifestações e formas de controle; exporem seus problemas e dificuldades, serem ouvidas, compreendidas, aceitas e respeitadas.

Eu acho que ainda falta saber mais informação de como o familiar pode lidar com o paciente esquizofrênico em casa, no dia-a-dia, ninguém vem para ver como é em casa [...] eu acho que devia ter muito mais informações (E2).

A presença de um familiar com esse tipo de doença provoca outras necessidades até então não manifestadas, como, por exemplo, determinar um cuidador, conviver com momentos estressantes de crise, entre outras. Pesquisadores perceberam, a partir da experiência em trabalhar com famílias, a importância da atenção dos profissionais para as necessidades daquelas famílias que convivem com a doença, principalmente no que concerne a orientações sobre a mesma, sobre os cuidados específicos requeridos. ${ }^{13}$ Destacam que muitas vezes o que mais aflige a família são pequenas coisas, resolúveis mediante simples orientações, as quais, depois de realizadas, deixam a família mais tranqüila e aliviada.

As famílias indicam a necessidade de uma comunhão de valores para poderem conviver, destacando a honestidade e o respeito como essenciais para um convívio harmonioso. Arrolaram, ainda, as famílias outras necessidades para viver bem, como: estabelecer relacionamentos consigo mesmo, com a família e com os demais. Nessa relação, é fundamental o respeito à individualidade, o reconhecimento das diferenças, a compreensão e a 
confiança entre seus membros. É ainda necessário haver uma comunicação efetiva entre os membros familiares, cada um levando em consideração o outro como um todo. ${ }^{9}$

Entendemos que, antes de propor uma assistência, o profissional determine o estado real das necessidades da família, o alvo dessas necessidades e as estratégias para sua satisfação. Para fazer isso, ele precisa envolver a família na assistência, compartilhar com ela os objetivos e metas, estabelecendo um diálogo efetivo que possa oferecer dados imprescindíveis ao delineamento de sua assistência.

Nas falas a seguir é possível perceber uma lacuna na área da saúde no que diz respeito às necessidades das famílias em situações de saúde ou de doença, o que demonstra que os profissionais não têm ainda a família como foco principal no tratamento.

[...] nunca me ensinaram alguma coisa, é bom os outros ensinarem a gente [...] algum médico, porque eles têm mais estudo que a gente (E3).

[...] eu nunca recebi, nunca falei com ninguém, nunca veio ninguém até a mim, nunca conversei sobre essa doença dela, não sei lidar com isso, nunca ninguém chegou a comentar nada comigo sobre esse assunto (E10).

Evidencia-se, através destas falas, que nem todas as categorias profissionais da área da saúde concebem família como parte de sua prática. Pensamos que, enquanto a família não for incluída no cuidado prestado ao portador de doença mental, este cuidado permanecerá no modelo tradicional, em que o profissional de saúde dita as regras ou age, apenas, a partir de seus pressupostos; parte daquilo que ele considera ser o melhor para aquele que tem uma doença mental e sua família, desconsiderando o que as pessoas envolvidas compreendem como sendo o melhor e o necessário para si mesmas.

Trabalhar com a família não é tarefa fácil, e exige uma análise acurada do contexto socioeconômico e cultural em que a mesma esteja inserida, analisando suas representações perante a sociedade, conhecendo a sua realidade de forma a desvendar o entendimento em família para que o conhecimento se funda à prática, de forma a superar os limites e possibilidades para a concretização das propostas. ${ }^{13}$

Mas por si mesmo de tanto a gente conviver mesmo com o sobe e desce da vida que a gente tem, a gente aprende por si mesmo, [...] porque orientação, ninguém aparece para dizer como a gente está, mas assim a gente já amadurece, mas é difícil receber orientação, vamos fazendo o que a gente sabe (E9).
Um dos fatores que possivelmente aumenta ainda mais o nível de ansiedade e confusão dos parentes responsáveis pelo tratamento de um paciente está ligado ao fato de que o campo da saúde mental é continuamente permeado por discussões, antagonismos e polêmicas entre profissionais da área, que repercutem no conjunto da sociedade. $\mathrm{Na}$ presença de uma crise psicótica, todas essas questões e disputas confundem ainda mais os familiares carentes de informação qualificadas. ${ }^{14}$

A maioria das pessoas não sabe como agir, quando precisam lidar com comportamentos estranhos e bizarros. Perdem o chão, ficam paralisadas quando alguém alucina. Não sabem se confortam, brigam ou colocam limites. Devem se calar ou fingir aceitar a realidade do outro, tão estrangeira ao mundo habitual. Ficam na dúvida, se precisam afastar os outros membros da família, principalmente os irmãos mais novos, se explicam ou não para o restante da família e para os amigos o que está acontecendo. ${ }^{14}$

Os resultados apontam que o contato com os familiares é necessário e indispensável, entretanto, as entrevistas evidenciam que a família é reduzida a um informante da vida de seu familiar doente. Idealmente o familiar deveria ser um aliado na execução do tratamento proposto, dividindo e construindo coletivamente - usuários, familiares e profissionais, um plano terapêutico, ou seja, o familiar deve ser co-partícipe do tratamento e da reabilitação.

\section{CONSIDERAÇÕES FINAIS}

Percebe-se que, historicamente, a família muitas vezes ficou afastada do tratamento do doente mental, porque este, na maioria das vezes, encontrava-se em hospitais psiquiátricos. Neste modelo, o familiar era alijado do tratamento, a proibição das visitas nas primeiras semanas de internação acabava reforçando a culpa da família. Nos serviços que operam no contexto da Reforma Psiquiátrica, observa-se a necessidade de a família estar ao lado do portador de transtorno mental, modificando comportamentos, aprendendo formas de manejo e interagindo com a equipe.

Através das entrevistas realizadas, os familiares revelaram sua preocupação em relação aos diversos comportamentos que ocorrem com o portador de transtorno mental. No momento em que acontecem as crises, muitas vezes ficam sem saber o que fazer ou tentam ajudar de alguma forma, porém, de maneira empírica. Percebe-se uma ausência de capacitação dos familiares em 
relação ao manejo da crise. A criação de grupos de educação em saúde periódica programada ou de psicoeducacionais abertos, voltados para a educação em saúde mental, propiciaria informações adequadas sobre a doença, prognóstico, formas de manejo, assim como, um espaço para os familiares externarem os sentimentos decorrentes dos encargos subjetivos e objetivos.

A partir do diagnóstico da doença houve a necessidade a incorporá-la a vida cotidiana, utilizando recursos adaptativos, como identificar um cuidador, lidar com os encargos objetivos e subjetivos de ter um membro acometido por um transtorno mental, o estigma e os sentimentos decorrentes. Muitos familiares apontam para o fato de sentirem-se culpados pela doença acometida a um membro da família. A culpa muitas vezes é uma marca visível na vida dessas pessoas. Com base no que foi exposto e nos depoimentos, conclui-se que os sentimentos dos familiares são heterogêneos e ambivalentes, mas acima de tudo existe preocupação com o bem-estar do portador de transtorno mental. Entendemos que, para a família, que é o alicerce fundamental das relações humanas, o fato de ter em seu núcleo um membro portador de transtorno mental ocasiona, para ambos, uma experiência crítica, avassaladora, que marca profundamente as suas vidas.

Os profissionais de saúde devem refletir sobre suas intervenções junto ao portador de transtorno mental e seus familiares e identificar as necessidades deste grupo. Sobretudo, devem trabalhar com o conceito de recuperação, um dos mais recentes acréscimos em reabilitação psiquiátrica. Para uma pessoa com uma longa história de doença mental, recuperação refere-se à reformulação de aspirações de vida e eventual adaptação à doença. Atualmente, o conceito e a importância de recuperação de doenças mentais severas são aceitos e reconhecidos por muitos setores e representam a promessa de esperança para o futuro.

\section{REFERÊNCIAS}

1. Pitta $A M F$, organizador. Reabilitação psicossocial no Brasil. 2a ed. São Paulo (SP): Hucitec; 2001.
2. Kaplan HI, Sadock BJ, Grebb JA. Compêndio de psiquiatria clínica. $9^{\mathrm{a}}$ ed. Porto Alegre (RS): Artes Médicas; 2007.

3. Espiridião E. Assistência em saúde mental: a inserção da família na assistência psiquiátrica. Rev Eletr Enferm [periódico na internet]. 2001[acesso em 2005 Abr 22]; 3(1): Disponível em: http:/ /www.fen. ufg.br/revista/revista3_1/samental.html.

4. Oliveira AMN de. Compreendendo o significado de vivenciar a doença na família: um estudo fenomenológico e hermenêutico [dissertação]. Florianópolis (SC): Universidade Federal de Santa Catarina. Programa de Pós-Graduação em Enfermagem; 2000.

5. Lefley HPA. Family perspective on rehabilitation. In: Flexer RW; Solomon, PL. organizador. Psychiatric rehabilitation in practice. St. Louis (USA): Elsevier Science \& Technology Books; 1993. p. 17-30.

6. Melman J. Família e doença mental: repensando a relação entre profissionais de saúde e familiares. São Paulo (SP): Escrituras; 2002.

7. Minayo MCS. O desafio do conhecimento: pesquisa qualitativa em saúde. São Paulo/ Rio de Janeiro (SP / RJ): Hucitec/Abrasco; 2000.

8. Ministério da Saúde(BR). Conselho Nacional deSaúde, Comissão Nacional de Ética em Pesquisa. Resolução No 196 de 10 de outubro de 1996: diretrizes e normas regulamentadoras de pesquisa envolvendo seres humanos. Brasília (DF): Ministério da Saúde; 1996.

9. Rosa L. Transtorno Mental e o cuidado na família. São Paulo (SP): Cortez; 2003.

10. Nasi C, Stumm LK, Hildebrandt LM. Convivendo com o doente mental psicótico na ótica familiar. Rev Eletr Enferm [periódico da internet]. 2004 [acesso em 2005 Abr 22]; 6(1): [9 p.]. Disponível em: http:/ / www. fen.ufg.br/revista/revista6_1/f6_ mental.html.

11. Macêdo VCD, Monteiro AR. Enfermagem e a promoção da saúde mental na família: uma reflexão teórica. Texto Contexto Enferm. 2004 Out-Dez; 13(4):585-92.

12. Berenstein I. Família e doença mental. São Paulo (SP): Escuta; 1998.

13. Waidman MAP, Elsen, I. Família e necessidades: revendo estudos. Acta Sci Health Sci. 2004; 26(1):147-57.

14. Waidman MAP, Elsen I, Moreira SK. Fatores que interferem na desinstitucionalização e reinserção do portador de transtorno mental na família. Arq Apadec. 2004; 8(Supl 1):21-8. 